\title{
HOW THE TYPE OF CONVEXITY OF THE CORE FUNCTION AFFECTS THE CSISZÁR $f$-DIVERGENCE FUNCTIONAL
}

\author{
MOHSEN KIAN
}

Abstract. We investigate how the type of convexity of the core function affects the Csiszár $f$ divergence functional. A general treatment for the type of convexity has been considered and the associated perspective functions have been studied. In particular, it has been shown that when the core function is MN-convex, then the associated perspective function is jointly MN-convex if the two scalar means $\mathrm{M}$ and $\mathrm{N}$ are the same. In the case where $\mathrm{M} \neq \mathrm{N}$, we study the type of convexity of the perspective function. As an application, we prove that the Hellinger distance is jointly GG-convex.

Mathematics subject classification (2010): Primary 26B25, 94A17; Secondary 26D15.

Keywords and phrases: Csiszár $f$-divergence, convexity and joint convexity, perspective function, numerical mean.

\section{REFERENCES}

[1] G. D. Anderson, M. K. Vamanamurthy and M. Vuorinen, Generalized convexity and inequalities, J. Math. Anal. Appl. 335 (2007), 1294-1308.

[2] I. Csiszár, Information Measures: A Critical Survey, Trans. 7'th Prague Conf. on Info. Th., Statist. Decis. Funct., Random Processes and 8'th European Meeting of Statist., Volume B, Academia Prague (1978), 73-86.

[3] I. CSISZÁR, Information-type measures of difference of probability distributions and indirect observations, Stud. Sci. Math. Hung. 2 (1967), 299-318.

[4] I. CsisZÁR And J. KöRner, Information Theory: Coding Theorems for Discrete Memory - less Systems, Academic Press, New York, 1981.

[5] S. S. DRAGOMIR, Hermite-Hadamard type inequalities for MN-convex functions, Aust. J. Math. Anal. Appl. 18 (2021), No. 1, Art. 1, 127 pp.

[6] S. S. DRAGOMIR, Inequalities for Csiszár $f$-divergence in information theory, RGMIA Monographs, Victoria University, 2000.

[7] S. S. Dragomir, Inequalities of Jensen type for AH-convex functions, J. Numer. Anal. Approx. Theory, 45 (2016), 128-146.

[8] G. L. Gilardoni, On Pinsker's and Vajda's type inequalities for Csiszár's $f$-divergences, IEEE Trans. Inf. Theory 56 (2010), 5377-5386.

[9] E. K. Godunova, Convexity of composed functions and its application to the proof of inequalities, Mat. Zametki 1 (1967), 495-500, (Russian).

[10] J.-B. Hiriart-URRUTy AND J.-E. MartíneZ-Legaz, Convex solutions of a functional equation arising in information theory, J. Math. Anal. Appl. 328 (2007), 1309-1320.

[11] M. KIAN, A characterization of mean values for Csiszár's inequality and applications, Indaga. Math. 25 (2014) 505-515.

[12] M. S. Moslehian And M. Kian, Jensen type inequalities for $Q$-class functions, Bull. Aust. Math. Soc. 85 (2012), 128-142.

[13] C. P. Niculescu, Convexity according to the geometric mean, Math. Inequal. Appl., 3 (2000), 155167.

[14] C. P. Niculescu And L.-E. Persson, Convex Functions and their Applications. A Contemporary Approach, Second Edition, CMS books in mathematics vol. 23, Springer-Verlag, New York, 2018. 
[15] I. SASON, On $f$-divergences: integral representations, local behavior, and inequalities, Entropy 20 (2018), 383.

[16] X.-M. Zhang, Y.-M. Chu And X.-H. ZhAng, The Hermite-Hadamard type inequality of GAconvex functions and its application, Journal of Inequalities and Applications, Volume 2010, Article ID 507560, 11 pages. 